\title{
Heme Polymerization Inhibition by Tithonia diversifolia (Hemsley) A.Gray Leaves Fractions as Antiplasmodial Agent and Its Cytotoxicity on Vero Cells
}

\author{
Rul Afiyah Syarif*, Mustofa, Ngatidjan, Mae Sri Hartati Wahyuningsih \\ Department of Pharmacology and Therapy, Faculty of Medicine, Public Health, and Nursing, \\ Universitas Gadjah Mada
}

\begin{abstract}
Previous research revealed that the extracts and fractions of Tithonia diversifolia (Hemsley) A.Gray leaves had antiplasmodial activity in vitro. For further development as an antiplasmodial agent, the mechanisms of action and safety of compounds are important to disclose. Heme polymerization inhibition is one of the main targets of antiplasmodial action. The aim of the study was to investigate the activity of $T$. diversifolia fractions in inhibiting heme polymerization and its cytotoxic effect on Vero cells. Heme polymerization inhibition assay from Bassilico and cytotoxic test on Vero cell using MTT method were conducted for three fractions (F5, F6, and F7) of T. diversifolia leaves. The inhibitory activity of heme polymerization expressed as $\mathrm{IC}_{50}$ and cytotoxicity effect expressed as $\mathrm{CC}_{50}$ were determined by probit analysis. The best heme polymerization inhibition activity was F5 with $\mathrm{IC}_{50}=162.20 \pm 57.81 \mu \mathrm{g} / \mathrm{mL}$ followed by F6 and F7 with IC $50216.30 \pm 26.56$ and $231.54 \pm 44.26 \mu \mathrm{g} / \mathrm{mL}$ respectively. All the fractions had a low cytotoxic effect with $\mathrm{CC}_{50}$ for F5, F6, and F7 were over than $100,34.81 \pm 9.94$ and $56.26 \pm 6.73 \mu \mathrm{g} / \mathrm{mL}$, respectively and the toxicity index fraction is below 10 or categorized as low selectivity. Conclusion: The fraction of T. diversifolia inhibited heme polymerization in vitro and had low cytotoxic effect on Vero cells but no selective toxicity. Further research using pure compounds may improve its selectivity.
\end{abstract}

Key words: Tithonia diversifolia; antiplasmodial; heme polymerization; cytotoxicity

\section{INTRODUCTION}

Malaria fever is an infection caused by Plasmodium and is the major cause of adults and children's death and disease in the tropics and the subtropics. Plasmodium falciparum is the species that causes most deaths compared with the other malaria-causing species such as $P$. vivax, $P$. ovale, and $P$. malariae. These days malaria control is conducted in the form of prevention (especially by maintaining Anopheles vector control) and by using antimalarial medication. Conventional treatment with monotherapy like chloroquine, amodiacin, sulfadoxine-pyrimethamine tend to be ineffective, and now the use of artemisinin-based combination therapy (ACT) is recommended. However, recently has surfaced P. falciparum resistance toward artemisinin in South East Asia, which encouraged the discovery of a new medicine as an alternative to address this resistance (WHO, 2015).

The success of concocting medicine rationally and the technique of making chemical medicines in the form of synthetic medicine from medicine factories make it easier to discover new medicines without exploring natural ingredients,

\footnotetext{
*Corresponding author : Rul Afiyah Syarif

Email : rulafiyah@ugm.ac.id
}

but it is important to note that natural ingredients and medical plantations are still the important source for new medicines (Lombardino and Lowe, 2004) like artemisinin and quinine that come from quinine stems and qinghao leaves (Artemisia annua). Tithonia diversifolia (Hemsley) A. Gray is one of the plantations that have been studied as antimalarials.

The previous study showed that fraction 6 (F6) of 7 fractions of $T$. diversifolia leaves performed the best antiplasmodium activity to $P$. falciparum strain FCR3 (Syarif et al., 2018). This antiplasmodium effect is related to the taginine lactone sesquiterpenes $\mathrm{C}$ contained in the plantation (Goffin et al,. 2002). One of the approaches that can be conducted for its development as an antimalaria alternative is by doing a research on biochemical process, which is highly needed for Plasmodium life sustainability, among others is studying its inhibition of Plasmodium hemozoin formation.

Hemozoin, known as malaria pigment, is a non-toxic heme crystal that is insoluble in water, and is produced in Plasmodium vacuole digestion. Hemozoin formation started from hemoglobin degradation. Hemoglobin degradation by aspartate protease (plasmepsin I) causes the decomposition 
of heme and globin. Globin is degraded by plasmepsin 2 (falcipain) becomes smaller peptides, which then to be changed by serine protease to amino acids, parasitic nutrition source. Free heme that is toxic to Plasmodium is polymerized to be hemozoin by polymerase heme. This inhibition of heme polymerase is one of the main targets of antimalarial medication (Kurosawa et al., 2000; Pandey and Clauhan, 1998). Some antimalarial medications that inhibit hemozoin formation are quinolines like chloroquine, amodiacin, and kinin (Kumar et al., 2007).

Based on the background of choosing this subject, present writer conducts this research o about the effects of $T$. diversifolia leaves fraction to the inhibition of heme polymerization and its cytotoxicity to Vero cell to find out its safety, in the hope of being able to be the foundation of the development of malaria medicines from natural ingredients.

\section{METHODOLOGY}

The tree marigold leaves (T. Diversifolia) are obtained from Sleman, Special Region of Yogyakarta and are identified in the Pharmaceutical Biology Laboratory in the Faculty of Pharmacy, Universitas Gadjah Mada. This research has been approved by the Ethics Commission of Faculty of Medicine, Universitas Gadjah Mada No KE/FK/18/EC. The making of fraction is conducted in the Pharmaceutical Biology Laboratory in the Faculty of Pharmacy, Universitas Gadjah Mada, and the inhibition test of heme polymerase and cytotoxicity are conducted in the Parasitology Laboratory in the Faculty of Medicine, Universitas Gadjah Mada.

\section{The Making of $T$. diversifolia Leaf Fraction (Hemsley) A. Gray}

This fraction is made of soluble ether extract of $T$. diversifolia leaves the same way it was conducted in the previous research (Syarif, et al., 2018). The making of soluble ether extract by separating the methanol extract of the leaves using ether solvent (Syarif et al., 2014). Soluble ether extract is fractionated using vacuum liquid chromatography. Silica gel GF254 as stationary phase and the mobile phase is: $\mathrm{n}$-hexane $(100 \%)$, n-hexane: ethyl acetate $(9: 1 \mathrm{v} / \mathrm{v}), \mathrm{n}$-hexane ethyl acetate $(8: 2 \mathrm{v} / \mathrm{v}), \mathrm{n}$-hexane: ethyl acetate $(7: 3 \mathrm{v} / \mathrm{v})$, n-hexane: ethyl acetate $(6: 4 \mathrm{v} / \mathrm{v}), \mathrm{n}$-hexane: ethyl acetate $(5: 5 \mathrm{v} / \mathrm{v})$, ethyl acetate $(100 \%)$ and chloroform: methanol $(1: 1 \mathrm{v} / \mathrm{v})$. Fractions obtained are then dried by having them aerated in room temperature. The image of the compounds that are contained in the fractions are shown in Thin Layer Chromatography (TLC). The fractions with similar spotting in TLC are merged until 7 fractions (F1-F7) are obtained. The previous research showed that $T$. diversifolia fractions had antiplasmodium activity with fraction 6 (F6) as the fraction with the best $\mathrm{IC}_{50}$ value (Syarif, et al., 2018). For the further development as antimalarial, this research conducts working mechanism test through the inhibition of heme polymerase and cytotoxicity test to Vero cell to find out its safety. These tests are also conducted to the closest fractions, which are F5 and F7 because these 3 fractions have the best antiplasmodium activity and similar compounds.

\section{Heme polymerase inhibition test}

Heme polymerase inhibition test is conducted using the method by Bassilico et al. (1998), which was modified. The in vitro hemozoin formation came from hematin in an acidic state that is converted to $\beta$-hematin, a polymer that is identical with hemozoin.

$100 \mu \mathrm{L}$ of $1 \mathrm{mM}$ hematin in $\mathrm{NaOH} 0.2 \mathrm{M}$ and $50 \mu \mathrm{L}$ of fractions (F5-F7) with various concentrations or distilled water (as negative control), and $50 \mu \mathrm{l}$ glacial acetic acid $100 \%$ is put into Eppendorf tube to start polymerase reaction. The trials repeated 3 times (triplicate) for every control and concentration of the treatment. Components in the tube are incubated in $37^{\circ} \mathrm{C}$ temperature for 24 hours to make the perfect heme polymerization and then are centrifuged $8000 \mathrm{rpm}$ for 10 minutes. Supernatant is disposed, and the sediment is washed with $200 \mu \mathrm{l}$ DMSO and is centrifuged $8000 \mathrm{rpm}$ for 10 minutes. The washing is conducted 3 times. Sediment is dissolved with $200 \mu \mathrm{l} \mathrm{NaOH} \mathrm{0,1} \mathrm{M.} \mathrm{Solvent}(100 \mu \mathrm{l})$ is poured into the microplate 96 well-its absorbency is read by Elisa Reader in the wave length of $405 \mathrm{~nm}$. Hemozoin concentrate ( $\beta$-hematin) calculated by comparing the test compounds absorbency with the standard curve.

\section{Cytotoxic effect test}

Cytotoxic effect is tested using method by Tada et al., (1986). $100 \mu \mathrm{L}$ of complete media [media $\mathrm{M}_{199}$ containing $10 \%$ FBS $+2 \%$ antibiotics (Penicillin-Streptomisin) $+0.5-1 \%$ antifungal Fungizon] and 10,000 Vero cells cultured in microplate 96 well -well. Microculture is incubated in $37^{\circ} \mathrm{C}$ in $\mathrm{CO}_{2}$ incubator for 24 hours then $100 \mu \mathrm{L}$ of fractions of various concentrations are put into the well. The control is the well filled with Vero cell and complete media (cell control or negative control) and the well filled with media without cell (media control). Microculture is incubated in $37^{\circ} \mathrm{C}$ in the $\mathrm{CO}_{2}$ incubator for 24 hours. After disposing 
the media, $100 \mu \mathrm{L}$ complete media and $10 \mu \mathrm{L}$ of Thiazolyl Blue tetrazolium Bromide is added to the well. Microplate is incubated in the $\mathrm{CO}_{2}$ incubator in $37^{\circ} \mathrm{C}$ temperature for 4 hours. $100 \mu \mathrm{L}$ of SDS $10 \%$ in CL $0.01 \mathrm{M}$ is added into the well to dissolve formazan.

Microplate is incubated for 18 hours in room temperature then read the absorbency with Elisa Reader at wave length $595 \mathrm{~nm}$. Death percentage of Vero cell with test compounds are calculated by comparing the absorbancy with the group absorbance without including test compounds.

\section{Statistic analysis}

Heme polymerase inhibition is expressed in Inhibitory Concentration Fifty Percent $\left(\mathrm{IC}_{50}\right)$ value while cytotoxic effect is expressed in Toxicity Concentration Fifty Percent $\left(\mathrm{TC}_{50}\right)$. Both are obtained with SPSS program probit log analysis.

\section{RESULTS AND DISCUSSION \\ Heme polymerase inhibition}

Life cycle of Plasmodium involves human and Anopheles mosquito as its habitat. When Plasmodium is developing in erythrocytes (intraerythrocytes) and in the tissue (exo-erythrocytes) inside the human body. While inside the erythrocytes, Plasmodium obtains the nutrition from cytoplasmic hemoglobin by pinocytosis (Kumar et al., 2007) and brings them to the vacuole in acidic state ( $\mathrm{pH}$ 5-5.4) to be degraded. In acidic state the hemoglobin is oxidized to be methemoglobin and then be hydrolyzed by aspartate protease enzyme (Plasmepsin I and II) to be free heme $\left(\mathrm{Fe}^{3+}\right)$ or ferriprotoporphyrin IX and denaturated globin. This globin is hydrolyzed to be smaller peptides by cystein protease (falcipain) and zinc that contains metallopeptidase (falcilisin). These peptides are carried by the peptide carrier that is located in vacuole digestion membrane into the parasitic cytoplasm to be hydrolyzed to be amino acids by cytoplasmic exopeptidase and then is used to synthesize protein (Coronado et al., 2014; Kumar et al., 2007).

Free heme $\left(\mathrm{Fe}^{3+}\right)$ produced from hemoglobin degradation is highly toxic because it can inhibit protease, damage the erythrocyte membrane (Pandey et al., 1998), produce reactive oxygen species (ROS) and induce oxidative stress that leads to lysis cells and parasite's death (Kumar et al., 2007). To resolve $\mathrm{Fe}^{3+}$ toxicity, Plasmodium has an ability to detoxify free heme. There are 2 ways of detoxification, the primary, which takes place in vacuole digestion by forming hemozoin and secondary, which takes place in cytosol by glutathione (GSH) and heme-binding protein
(Campanale et al., 2003; Becker et al., 2004), and free heme degradation by $\mathrm{H}_{2} \mathrm{O}_{2}$ (Nagababu et al., 2003). Primary way through hemozoin formation is the most important mechanism of free heme detoxification in Plasmodium sp. (Kumar et al., 2007).

Free heme detoxification to be hemozoin ("malaria pigment") is carried out by heme polymerase enzyme (Coronado et al., 2014) that changes heme monomer to heme polymer (hemozoin). Heme polymer is inter-connected with iron-carboxylase bonds that connect the center ferri from one heme with propionate side chains from other heme (Image 1) (Pandey et al., 1998).

Hemoglobin degradation is found from the ring stage but mostly this metabolic activity occurs in trophozoite and schizone stages. As long as the ring is only at stage Plasmepsin I, the enzyme that degrade the hemoglobin becomes the heme and goblin that are found, and its existence continues until schizone stage. Plasmepsin II is mostly expressed in trophozoite phase as the phase with the most active metabolism (Coronado et al., 2014).

This research conducts in vitro heme polymerization heme test by adding $\mathrm{T}$. diversifolia fraction and glacial acetic acid to hematin solvent (Bassilico et al., 1998). Glacial acetic acid is useful to make the acid state identical to the state inside vacuole digestion and also to start the heme polymerization process. The more inhibited the heme is, the less hemozoin is formed. The test result showed that giving F5, F6, and F7 inhibit the formation of $\beta$-hematin (hemozoin). The more concentration, the bigger the inhibition percentage. The inhibition ability of heme polymerization is expressed with $\mathrm{IC}_{50 \text {.value. }}$ Fraction 5 has the best heme polymerization inhibition activity with $\mathrm{IC}_{50}$ value $=162.20 \pm 57.81$ $\mu \mathrm{g} / \mathrm{mL}$ followed by $\mathrm{F} 6$ and $\mathrm{F} 7$ with $\mathrm{IC}_{50}$ value respectively $216.30 \pm 26.56$ and $231.54 \pm 44.26$ $\mu \mathrm{g} / \mathrm{mL}$ (Table I). Anova test showed that there was no significant difference of $\mathrm{IC}_{50}$ average between the three fractions ( $p>0.05)$.

The ability to inhibit heme polymerization as one of the $\mathrm{T}$. diversifolia antiplasmodium mechanisms is connected because of the tagitinin $\mathrm{C}$ lactone sesquiterpenes inside the plantation (Goffin et al., 2002). Lactone sesquiterpenes is able to enter the cell by diffusion (Ganthous et al., 2010). The inhibition of heme polymerization by T. diversifolia fraction is fathomed to go through the similar mechanism with chloroquine. Chloroquine enters the vacuole digestion by diffusion. While inside the vacuole, chloroquine is protonized (with positive charge) so when the 
Table I. Hematine level average, heme polymerization inhibition percentage, and the $\mathrm{IC}_{50}$ of $T$. diversifolia fractions heme polymerization inhibition

\begin{tabular}{cccc}
\hline Compounds & Concentration $(\boldsymbol{\mu g} / \mathbf{m L})$ & Level average $\boldsymbol{\beta}$-hematin $(\mathbf{m M})$ & Inhibition average $(\%)$ \\
\hline F5 & 25 & $10.75 \pm 0.36$ & $10.36 \pm 3.03$ \\
& 100 & $9.32 \pm 0.25$ & $22.29 \pm 2.09$ \\
& 200 & $3.70 \pm 1.90$ & $69.18 \pm 15.88$ \\
F6 & 25 & $11,41 \pm 0,37$ & $4.87 \pm 3.08$ \\
& 100 & $9,73 \pm 1,27$ & $18.83 \pm 10.54$ \\
F7 & 200 & $5,87 \pm 0,41$ & $51.01 \pm 3.41$ \\
& 25 & $11.64 \pm 0.64$ & $2.92 \pm 5.34$ \\
& 100 & $10,43 \pm 0,67$ & $13.04 \pm 5.58$ \\
& 200 & $5.98 \pm 1.58$ & $50.16 \pm 13.18$ \\
\hline
\end{tabular}

Table II. IC 50 value of the growth of P. falciparum strain FCR 3 and heme polymerization inhibition

\begin{tabular}{lcc}
\hline Compounds & $\begin{array}{c}\text { The average of } \mathrm{IC}_{\mathbf{5 0}} \pm \mathrm{SD}(\boldsymbol{\mu g} / \mathbf{m L}) \text { in } \boldsymbol{P} . \\
\text { falciparum strain FCR } \mathbf{3}(\mathrm{Syarif} \text { et al., 2018) }\end{array}$ & $\begin{array}{c}\text { The average of } \mathrm{C}_{50} \pm \mathbf{S D}(\boldsymbol{\mu g} / \mathbf{m L}) \\
\text { of heme polymerization inhibition }\end{array}$ \\
\hline F5 & $36.54 \pm 2.16$ & $162.20 \pm 57.81$ \\
F6 & $13.63 \pm 1.43$ & $216,30 \pm 26,56$ \\
F7 & $23.27 \pm 2.07$ & $231.54 \pm 44.26$ \\
\hline
\end{tabular}

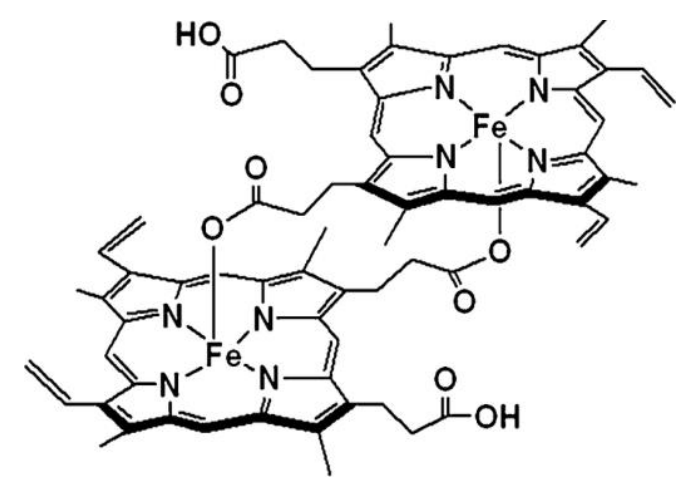

Figure 1. Hemozoin structure (Carney et al., 2006)

electricity charge changes, the chloroquine may not diffuse back outside of the vacuole. This causes chloroquine to accumulate in the vacuole digestion. Compared with the chloroquine sensitive parasite, the accumulation of chloroquine in the vacuole digestion is relatively less in chloroquine resistant Plasmodium (Ehlgen et al., 2012).

Chloroquine in vacuole digestion bond with heme to forming heme-chloroquine complex and inhibit heme polymerization. Other antimalarials like artemisinin and primaquine also bind hemes but the complex that is formed does not have the ability to inhibit heme polymerization (Sullivan et al., 1998). Therefore heme polymerase inhibition is not only determined by the ability of compounds bonding with hemes but also their ability to inhibit hemes to polymerize with other hemes.
Compared with the $\mathrm{IC}_{50}$ value on $P$. falciparum strain FCR3 (Syarif et al., 2018) the result of this research shows that the $\mathrm{IC}_{50}$ value of heme polymerase inhibition is bigger (Table II). This is similar with the research by Huy et al., (2007) that stated that IC $_{50}$ values of chloroquine and butylprimaquine on P. falciparum D6 are respectively 0.3 and $0.1 \mu \mathrm{M}$ while the $\mathrm{IC}_{50}$ of hemozoin formation are 15.4 and $2.9 \mu \mathrm{M}$ (Huy et al., 2007). IC $\mathrm{C}_{50}$ value of heme polymerase is bigger than the $\mathrm{IC}_{50}$ of $\mathrm{P}$. falciparum because there is no direct connection between antiplasmodium activity and hemozoin formation exhibition unless the compound's pKa and lipophilicity are determined (Egan et al., 2000) and high concentration for the compound is needed inside the vacuole digestion compared with the one inside the plasma as the one occurs in the chloroquine. Quinoline concentration is found in vacuole digestion in millimolar stage, although the ones in the plasma are in nanomolar stage (Chong and Sullivan, 2003).

\section{Cytotoxic test}

Adding fractions (F5, F6, and F7) to Vero cell culture shows that the more concentration is given, more cells die or in other word they become more toxic to the cell, and it depends on the fraction concentration that is given (Image 2). Cytotoxic test is conducted to find out if the fraction is safe and is not toxic to normal cell.

Fraction 5, F6, and F7 is cytotoxic, with 50\% Cytotoxic Concentration $\left(\mathrm{CC}_{50}\right)$ respectively $>100$; 


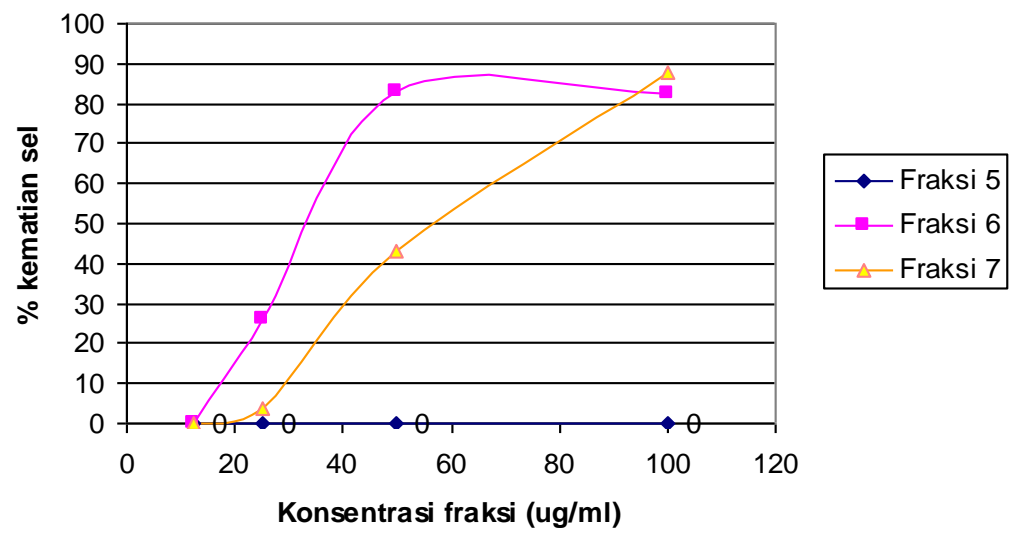

Figure 2. Death percentage of Vero cells that were given $T$. diversifolia leaves fraction in various concentrations

Table III. T. diversifolia leaves fractions $\mathrm{TC}_{50}$ in Vero cell

\begin{tabular}{cccc}
\hline Fraction & $\begin{array}{c}\mathbf{C C}_{\mathbf{5 0}} \pm \mathbf{S D}(\boldsymbol{\mu g} / \mathbf{m L}) \\
\text { average }\end{array}$ & $\begin{array}{c}\mathbf{I C}_{\mathbf{5 0}} \pm \mathbf{S D}(\boldsymbol{\mu g} / \mathbf{m L}) \text { average } \\
\text { (Syarif } \text { et al., } \mathbf{2 0 1 8} \text { under review) }\end{array}$ & $\begin{array}{c}\left.\mathbf{( C C}_{\mathbf{5 0}} / \mathbf{I C}_{\mathbf{5 0}}\right) \text { selectivity } \\
\text { Index }\end{array}$ \\
\hline Fraction 5 & $>100$ & $36.54 \pm 2.16$ & $>2.7$ \\
Fraction 6 & $34.81 \pm 9.94$ & $13.63 \pm 1.43$ & 2.55 \\
Fraction 7 & $56.26 \pm 6.73$ & $23.27 \pm 2.07$ & 2.42 \\
\hline
\end{tabular}

$34.81 \pm 9.94$ and $56.26 \pm 6.73 \mu \mathrm{g} / \mathrm{mL}$ (Table III), the three fractions are categorized under fractions that have low cytotoxic effects $\left(\mathrm{TC}_{50}>30 \mu \mathrm{g} / \mathrm{mL}\right)$ to Vero cell (Jenett-Siems et al., 1999). Based on the average $\mathrm{t}$-test the $\mathrm{CC}_{50}$ of $\mathrm{F} 6$ is significantly lower than F5 and F7 $(\mathrm{p}<0.05)$.

The development of the new medicine prioritize the selective compound, which is a compound that only inhibits essential biological process for the parasite breeding and is not toxic to its host. The selectivity index or toxicity index value is calculated by comparing $\mathrm{CC}_{50}$ with $\mathrm{IC}_{50}$. Ratio under 10 indicates that cytotoxic is not selective (Jenett-Siems et al., 1999). From this research is obtained the toxicity index for F5, F6, and F7 is less than 10, which means the three fractions are nor selective, toxic to both Plasmodium and its host cell. Toxicity index value is low because these fractions are not yet pure compounds or they still contain too many compounds. Therefore, they are not safe enough to be developed as the natural ingredients for antimalaria.

Tithonia divevrsifolia may be developed as safer antimalarial medicine by finding pure compound, which is expected to provide maximum therapy effect and minimum cytotoxic effect like chloroquine and artemisinin, which are also natural ingredients. The fraction that can be examined further to obtain pure compound from among those fractions are F6 because these fraction has the best antiplasmodium activity and better cytotoxic index compared with F7.

\section{CONCLUSION}

T. diversifolia fraction inhibits in vitro heme polymerization inhibition and has low cytotoxic effect in Vero cell but not selective. Further research using pure compounds may improve its selectivity.

\section{ACKNOWLEDGEMENTS}

Thank you to National Institute of Health Research and Development, Ministry of Health of the Republic of Indonesia (Litbangkes Depkes RI) for funding this research through Risbin Iptekdok 2006, Parasitology Laboratory of Faculty of Medicine of Universitas Gadjah Mada as the place for conducting this research, and Dr. dr. Mahardika Agus Wijayanti, FTM \& H., M. Kes for her support for this research.

\section{REFERENCES}

Bassilico, N., Pagani, E., Monti, D., Olliaro, P., and Taramelli, D., 1998, A microtitre-based method for measuring the Haem Polimerization Inhibitory Activity (HPIA) of antimalarial drugs, J. Antimicrob. Chemother. 42:55-60.

Becker, K., Tilley, L., Vennerstrom, J.L., Roberts, D., Rogerson, S., Ginsburg, H. 2004. Oxidative 
stress in malaria parasite-infected erythrocytes: host-parasite interactions. Int. J. Parasitol. 34(2):163-89.

Campanale, N., Nickel, C., Daubenberger, C.A., Wehlan, D.A., Gorman, J.J., Klonis, N., Becker, K., Tilley, L. 2003. Identification and characterization of heme-interacting proteins in the malaria parasite, Plasmodium falciparum. J. Biol. Chem. 278(30): 27354-27361.

Carney, C.K., Harry, S.R., Sewell, S.L.,.Wright, D.W. 2007. Detoxification biominerals. Top. Curr. Chem. 270: 155-185.

Chong, C.R and Sullivan, D.J. 2003. Inhibition of heme crystal growth by antimalarials and other compounds: implications for drug discovery. Biochem. Pharmacol. 66: 22012212.

Coronado, L.M., Nadovich, C.T., and Spadafora, C. 2014. Malarial hemozoin: from target to tool. Biochim. Biophys. Acta. 1840(6): 20322041.

Egan, T.J., Hunter, R., Kaschula, C.H., Marques, H.M., Misplon, A., Walden, J. 2000. Structurefunction relationships in aminoquinolines: effect of amino and chloro groups on quinoline-hematin complex formation, inhibition of beta-hematin formation, and antiplasmodial activity. J. Med. Chem. 43(2):283-291.

Ehlgen, F., Pham, J.S., Koning-Ward, T., Cowman, A.F., Ralp, S.A. 2012. Investigation of the Plasmodium falciparum food vacuole through inducible expression of the Chloroquine Resistance Transporter (PfCRT). PLoS ONE. 7(6): 1-12.

Ghantous, A., Gali-Muhtasib, H., Vuorela, H., Saliba, N.A., and Darwiche, N. 2010. What made sesquiterpene lactones reach cancer clinical trials? Drug Discovery Today. 15 (15/16): 668-678.

Goffin, E., Ziemons, E., de Mol, P., de Madureira Mdo, C., Martins, A.P., da Cunha, A.P., Phillippe, G., Tits, M., Angenot, L., and Frederich, M. 2002. In vitro antiplasmodial activity of Tithonia diversifolia and identification of its main active constituent : taginin C. Planta Med., 68(6): 543-5.

Huy, N.T., Mizunuma, K., Kaur, K., Nhien, N.T.T., Jain, M., Uyen, D.T., Harada, S., Jain, R., and Kamei, K. 2007. 2-tert-Butyl-8quinolinamines exhibit potent blood schizontocidal antimalarial activity via inhibition of heme crystallization.
Antimicrob. Agents Chemother. 51(8): 28422847.

Jenett-Siems, K., Mockenhaupt, F.P., Bienzle, U., Gupta, M.P., and Eich, E. 1999. In vitro antiplasmodial activity of Central American medicinal plants. Trop. Med. Intl. Health., 4(9): 611-615.

Kumar, S., Guha, M., Choubey, V., Maity, P., Bandyopadhyay, U. 2007. Minireview antimalarial drugs inhibiting hemozoin $(\beta$ hematin) formation: A mechanistic update. Life Sci. 80: 813-828.

Kurosawa,Y., Dorn, A., Kitsuji-Shirane, M., Shimada,H., Satoh,T., Matile, H., Hofheinz, W., Masciadri, R., Kansy, M., and Ridley, R.G. 2000. Hematin polymerization assay as a high-throughput screen for identification of new antimalarial pharmacophores. Antimicrob. Agents Chemother. 44 (10): 2638-2644.

Lombardino, J.G. and Lowe, J.A. 3rd. 2004.The role of the medicinal chemist in drug discovery then and now. Nat. Rev. Drug Discov. 3(10): 853-862.

Nagababu, E., Chrest, F.J., Rifkind, J.M. 2003. Hydrogen-peroxide-induced heme degradation in red blood cells: the protective roles of catalase and glutathione peroxidase. Biochim. Biophys. Acta. 1620(13): 211-217.

Pandey, A.V. dan Chauhan, V.S. 1998. Heme polymerization by malarial parasites: a potential target for antimalarial drug development. Current Science. 75 (9): 911918.

Syarif, R.A., Wahyuningsih, M.S.H., Mustofa, Ngatidjan. 2014. Aktivitas penghambatan Ekstrak terpurifikasi Daun Kembang Bulan (Tithonia diversifolia [Hemsley] A.Gray) pada Pertumbuhan Plasmodium falciparum dan Polimerase Heme. J. Indon. Med. Assoc. 64(5): 228-233.

Syarif, R.A., Wahyuningsih, M.S.H, Mustofa, Ngatidjan. 2018. Antiplasmodial activity and onset speed of growth inhibition of Tithonia diversifolia (Hemsley) A.Gray leave fractions on Plasmodium falciparum. Trop. J. Pharm. Res. under review.

Tada, H., Shiho, O., Kuroshima, K., Koyama, M., and Tsukamoto, K. 1986. An improved colorimetric assay for interleukin 2. J. Immunol. Methods. 93(2):157-165.

WHO. 2015. Guideline for the Treatment of Malaria. $3^{\text {th }}$ Ed. 20 Avenua Appia, 1211 Geneva 27, Switzerland. WHO Press. 